the flash of capital 


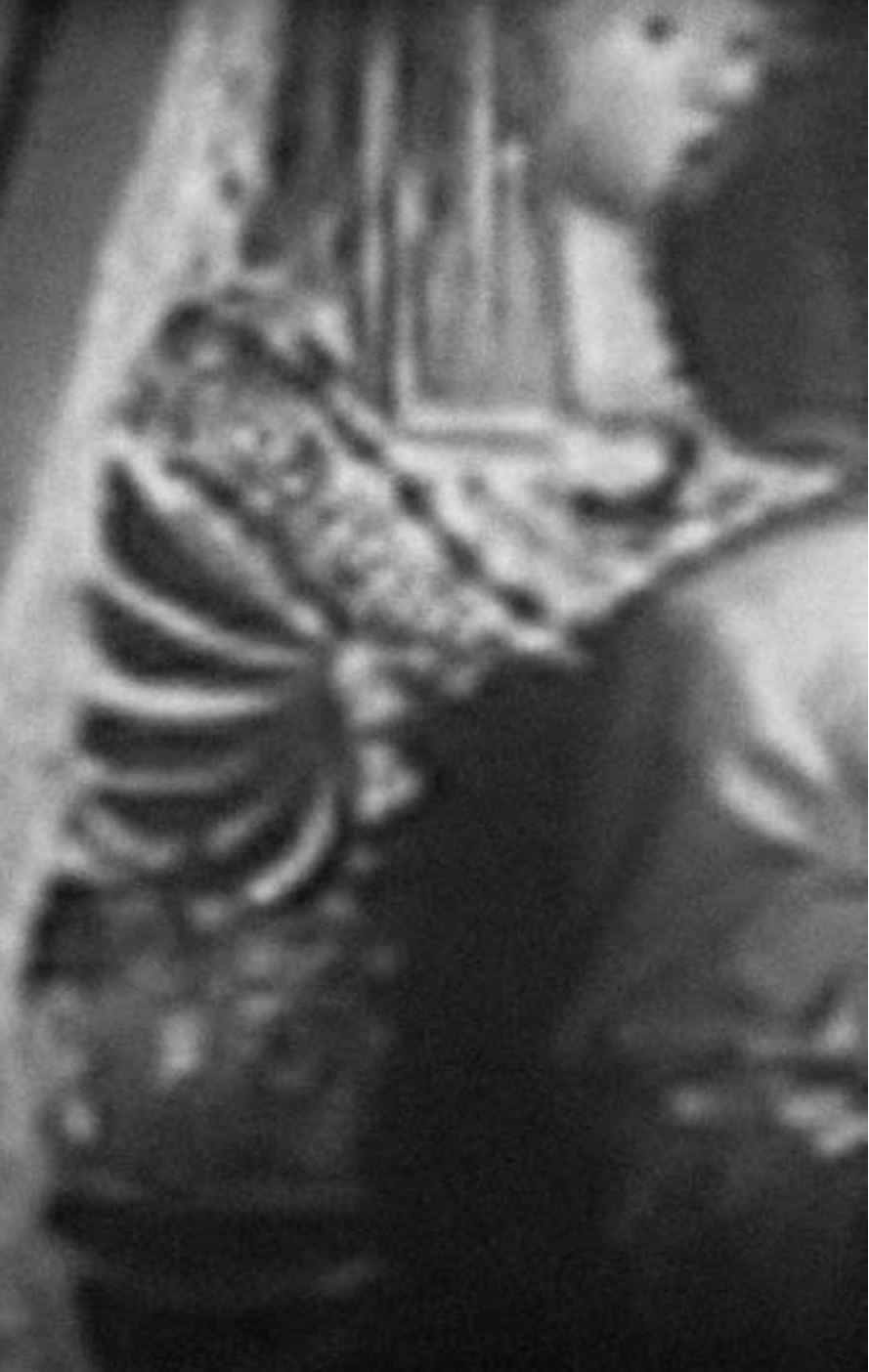

Asia-Pacific

Culture, Politics, and Society

Editors: Rey Chow, H. D. Harootunian,

and Masao Miyoshi 
ERIC CAZDY N

\section{the flash of capital}

Film and Geopolitics in Japan

Duke University Press Durham $\leftrightarrow$ London 2002 
(C) 2002 Duke University Press All rights reserved

Printed in the United States of America on acid-free paper @ Designed by Rebecca Giménez Typeset in Trump Medieval by Tseng Information Systems Library of Congress Cataloging-inPublication Data appear on the last printed page of this book. 